\title{
Effects of the Photovoltaic Distributed Generation on Electricity Distribution System Voltage - Updated Review
}

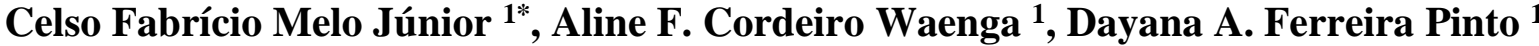 \\ ${ }^{1}$ Universidade Tecnológica Federal do Paraná, Curitiba, Brasil.
}

\begin{abstract}
Concerns about the environment and a growing demand for electricity have led to the intensive search for renewable energy sources. Photovoltaic solar energy, in the form of distributed generation, has shown a very high growth rate to an extent that in some regions it will be adopted on a large scale, thus being responsible for the supply of a significant portion of the load of this region. Some factors have favored the adoption of distributed generation: the drop in the price of solar panels and inverters, as well as its easy installation and maintenance. However, the largescale adoption of solar distributed generation brings new challenges to the power distribution system. Network voltage control is an example. In conventional systems, voltage control is a properly addressed problem, but in networks with the presence of distributed generation, where at certain times of the day reverse energy flows can be observed, more detailed studies on voltage behavior are necessary concerning the power quality. This article makes an analysis of relevant studies on the effects that the insertion of photovoltaic distributed generation can cause in the voltage of the electric power distribution system under the optics of two phenomena: the fluctuation and the voltage ripple.
\end{abstract}

Keywords: Photovoltaic distributed generation, voltage ripple, flicker, power quality.

*Author of correspondence: celso@profcelso.org 


\section{INTRODUCTION}

Photovoltaic (PV) distributed generation (DG) has grown exponentially since the global PV capacity was $40 \mathrm{GW}$ in $2010^{11}$ and this number jumped to $303 \mathrm{GW}$ in 2016 and came to represent about $47 \%$ of renewable energy installed ${ }^{10}$, an increase of approximately $758 \%$ compared to 2010 .

Given the increasing adoption of this type of energy generation, it is interesting to see what effects the large-scale insertion of GD PV can cause in the voltage distribution system. In Brazil, despite some incentives from the government, the installed capacity of GD FV (21 MW in 2015) can still be considered insignificant in the electricity matrix considering that it represents less than $0.02 \%$ of the total installed capacity of 140,858 MW ${ }^{3}$. In general, there are few cases in which DG PVs meet a significant portion of the grid's demand, so the effects of the large-scale insertion of this source are little known and in this article some simulation-based studies will be presented.

Distributed photovoltaic generation in moments of excess generation, without the accumulation in batteries, can generate a reverse energy flow in the network, causing changes in the voltage profile.

Traditionally, the distribution system has a one-way configuration coming from the substation transformer to the feeders. The voltage fluctuations can be large because of the intermittent solar irradiation causing the output power to be varied, in addition to the profile of the connected loads ${ }^{2}$.

In general, it can be said that the current known problems regarding voltage variation in the distribution system have already been mitigated. However, such problems may arise again due to the high insertion of the DG PV in the network.

\section{MATERIAL AND METHODS}

The effects of large-scale GD insertion in distribution systems are still under review and the results of the studies in many cases are controversial. For the accomplishment of this work about 150 recent articles were analyzed and therefore the recent and relevant data served as a research base. The careful analysis of these articles and the compatibility of the main information obtained both in field tests and in simulations led to the results summarized below.

\section{RESULTS AND DISCUSSION}

DG PV is characterized by intermittent solar irradiation and fluctuations in power generated relatively quickly due to the passage of clouds above the panels and other projected shadows. This may result in voltage fluctuations in the network. These variations shall be limited in order to maintain the voltage within the allowable limits for each component of the distribution network, such as voltage regulators, capacitor bank and transformer tap switches ${ }^{7}$. Such variations occur through two distinct phenomena: ripple and voltage fluctuation. 


\section{Effects of Ripple on Network Voltage}

The definition of ripple is given by ${ }^{12}$ as momentary increases in voltage values at nominal frequency, beyond tolerances with durations of more than one cycle, but less than a few seconds.

According to an article published by ${ }^{14}$ the phenomenon of voltage ripple has been known from the distribution system for some years and it can be said that for a conventional system it is already technically mitigated. However, with the insertion of DV PV into large scale, the ripple may recur. As for this study, the authors determined that the voltage ripple rate for a system with 50\% energy supply for the load from photovoltaic generation did not exceed the value of $1.4 \%$ without using any control adjustment, that is, use of capacitors or switches in transformers. The system was simulated in PCFLO software capable of performing harmonic, short circuit and load flow calculations. According to the authors, the effects of the ripple on the network voltage depend not only on the degree of penetration of the DG PV and the electrical rigidity of the network, but also on the intensity of the winds that influence how quickly the clouds can cover the photovoltaic systems.

To obtain such results, the authors used cloud modeling and considered the maximum power output of solar panels on days of bright sun, blue sky, and white cumulus clouds.

\section{Effects of Fluctuation in Network Voltage}

The voltage fluctuation also known as flicker is defined as a random, repetitive or sporadic variation of the effective value of the voltage ${ }^{\text {. }}$

According to ${ }^{5}$, systems without battery storage provide energy when there is solar irradiance. In this case, the power transmitted by the photovoltaic system can suffer rapid oscillations with the passage of clouds. One solution found for this effect is transformer tap control in substations. However, this maneuver will adjust the voltage levels in all the feeders connected to the bar, even if they have not been affected by the voltage change caused by the DG PV ${ }^{4}$.

According to ${ }^{14}$, in a case where DG PV meets the demand of $50 \%$ of the total load in the distribution system, the voltage fluctuation rate is in the range of $0.5 \%$ to $2 \%$ at the end of the feeders. According to the authors, this rate depends on the distance between the substation and the distributed PV generators. This study was developed as a function of a simulation of five North American feeders using the EPRI's Open DSS software and it was assumed that the inverters did not provide reactive power and could quickly track the power oscillations caused by the differences in solar incidence in systems.

In $2013,{ }^{6}$ a study on this subject was carried out, and for such analysis, the electrical network was considered unbalanced, with the insertion of small PV systems and in large part with dynamic load. According to the study, the methods for mitigation of voltage increase can be divided into two large groups:

1) Control by the optics of the photovoltaic panels: Active power control, active overpower buffer, reactive power control, power control applications, etc.

2) Control by the optics of the electrical network: Installation of autotransformers along the line, reduction of secondary substation voltage, etc.

For $^{2}$, one of the ways to mitigate voltage fluctuation in a low voltage network is by controlling reactive power through injection or absorption (both limited by the 
classification of intelligent inverters and they must have bi-directional communication capability) inverters, which are used to regulate the voltage.

In a study of ${ }^{7}$, a model was created based on actual data from a $13.2 \mathrm{kV}$ network with 2,751 consumer households. In the simulations, three different conditions were considered: maximum load, maximum PV generation and maximum difference between load and generation. The occurrence of over voltages has been observed and how the voltages oscillate throughout the day. The effects on the intermittent voltage of the PV generation caused by cloud cover were evaluated. We also tested power factor control and PV generation control strategies. The obtained results showed that both the voltage imbalances and the active and reactive losses are improved after insertion of the DG $\mathrm{PV}$, with a maximum voltage variation of $\pm 2 \%$.

According to ${ }^{8}$, the insertion of DG from renewable sources can cause problems with the voltage fluctuation in the distribution network, whether they are over voltages in the periods of surplus generation or sub tensions at night or in periods of low generation. According to the authors the safest solution, despite costlier, would be the coupling of energy storage in batteries. This system would work with batteries or supercapacitors storing energy during the day, in the generation period exceeding the consumption, to avoid over voltage in the network. This stored energy would be gradually returned to the distribution network overnight, when the consuming load requires more energy. This would avoid under voltage and would also cooperate for reactive control.

The solution of storage of surplus energy in lead-acid or lithium-ion batteries, used as a strategy for voltage control, was also defended by ${ }^{1}$. The study was based on data from Germany where, in 2013, there were $34.8 \mathrm{GWp}$ of DG PV installed. Due to the problems of over voltage and reverse flow caused by the high insertion of DG PV, the author tried to demonstrate the feasibility, including the economic aspect, of the use of energy storage systems in batteries (self-consumption), these batteries are designed for 5 to 6 $\mathrm{kWp}$ PV systems. According to ${ }^{1}$ the use of storage in batteries reduces the levels of over voltage since it decreases the energy injection in the network. The author concludes that the most attractive solution to the problem of over-voltage is self-consumption. Based on this study, the German government has established a program of granting loans and subsidies of up to $€ 600$ per $\mathrm{kWp}$ installed PV generation with battery storage system ${ }^{1}$. However, additional problems are introduced by the adoption of battery storage, in addition to their cost: greater operational and maintenance complexity, as well as problems involving the disposal of batteries, which if done improperly can cause socio-environmental impacts, representing risks to human health and mainly due to the possibility of contamination of soil and groundwater ${ }^{13}$.

\section{CONCLUSIONS}

As shown in this paper the large-scale insertion of DG PV may bring technical challenges for voltage control in distribution networks. This is a new situation for energy utilities, and studies on the subject are incipient and often based on simulations. However, this is considered an irreversible trend.

Regarding the voltage ripple that we have, this phenomenon depends on both the DG PV entry level in the system as the intensity of the winds influence the shading caused by clouds. It is observed that the ripple can occur on a small scale, $1.4 \%$, in systems with high DG insertion. 
In the case of voltage fluctuations, it was found in the studies analyzed that the maximum voltage variation did not exceed $2 \%$ and there are proposed solutions either by optical inverter or for the optical network (autotransformers installation along the line, switching taps in the secondary substation, etc.). In addition, in relation to the voltage variation resulting from reverse power flow, the use of batteries can be used to store surplus energy.

The solutions discussed here are in different stages of development and may eventually be adopted to solve problems of voltage variations in the network. Consequently, potential negative effects resulting from the insertion of distributed photovoltaic generation should not discourage the increasing adoption of this energy source.

\section{REFERENCES}

1- Appen JV, Stetz T, Braun M, Schmiegel A. Local Voltage Control Strategies for PV Storage Systems in Distribution Grids. IEEE Transactions on Smart Grid, vol. 5. nº 2, 2014.

2- Chanhome A, Chaitusaney S. Voltage Fluctuations Relief by Applying VAr Control Scheme Function. Electrical Engineering/Electronics, Computer, Telecommunications and Information Technology (ECTI-CON), 13th International Conference on, 2016.

3- EPE. BALANÇO ENERGÉTICO (Energetic Balance) 2016 - 2015: Synthesis. Available in <https://ben.epe.gov.br/downloads/S\%C3\%ADntese\%20do\%20Relat\%C3\%B3rio\%20Final_2 016_Web.pdf>. Accessed in: 01 de jul de 2017.

4- Grady MW, Thomas H, Razon A. An evolution procedure for estimating voltage ripple caused by cloud shadows moving over high-penetration PV distribution networks. Baylor University and U.S. Department of Energy, 2014.

5- Grabolle PB. A integração de sistemas solares fotovoltaicos em larga escala no sistema elétrico de distribuição urbana (The integration of solar photovoltaic systems on a large scale in the urban electricity distribution system). Doctoral thesis - Universidade Federal de Santa Catarina. Florianópolis, 2010.

6- Hashemi NM, Agelidis V. Evaluation of voltage regulation mitigation methods due to high penetration of PV generation in residential areas. International Conference on Renewable Energy Research and Applications, 2013.

7- Jung J et al. Local Steady-state and quasi steady-state impact studies of high photovoltaic generation penetration in power distribution circuits. Elsevier Ltd. 2015. Available in <http://www.sciencedirect.com/science/article/pii/S1364032114009496>. Accessed in: 15 abr 2016.

8- Manzoni A, Castro R. Microgeneration Impact on LV Distribution Grids: A Review of Recent Research on Overvoltage Mitigation Techniques. International Journal Of Renewable Energy Research, 2016.

9- PRODIST (Procedimentos de Distribuição de E nergia Elétrica no Sistema Elétrico Nacional). Módulo 8 - Qualidade da Energia Elétrica (Module 8 - Quality of Electric Energy). Aneel - Agência Nacional de Energia Elétrica, 2010.

10- REN21 (Renewable Energy Policy Network for the 21st Century). Renewables 2017 Global Status Report. Paris: REN21, Secretariat, 2017.

11- REN21 (Renewable Energy Policy Network for the 21st Century). Renewables 2011 Global Status Report. Paris: REN21, Secretariat, 2011.

12- Trevisan AS. Efeitos da geração distribuída em sistemas de distribuição de baixa tensão (Effects of distributed generation on low voltage distribution systems). Completion of course work - Universidade Federal do Paraná, Curitiba, 2011.

13- Tomalsquim MT. Energia Renovável: Hidráulica, Biomassa, Eólica, Solar, Oceânica (Renewable Energy: Hydraulics, Biomass, Wind, Solar, Ocean). EPE. Rio de Janeiro, 2016.

14- Tzartev R, Grady M. Impact of High Penetration PV on distribution feeders. IEEE PES Innovative Smart Grid Technologies Europe (ISGT Europe), 2012. 